\title{
Correction to: Relationship of the knee extensor strength but not the quadriceps femoris muscularity with sprint performance in sprinters: a reexamination and extension
}

Miyuki Hori ${ }^{1}$, Tadashi Suga ${ }^{1 *}$, Masafumi Terada', Takahiro Tanaka' ${ }^{1}$ Yuki Kusagawa' ${ }^{1}$ Mitsuo Otsuka²,

Akinori Nagano ${ }^{1}$ and Tadao Isaka ${ }^{1}$

Correction to: BMC Sports Sci Med Rehabil 13, 67 (2021)

https://doi.org/10.1186/s13102-021-00293-1

Following publication of the original article [1], the authors reported an error in the affiliations of their article. The correct affiliations are:

1. Faculty of Sport and Health Science, Ritsumeikan University, Kusatsu, Shiga, Japan.

2. Faculty of Sport Science, Nippon Sport Science University, Yokohama, Kanagawa, Japan.

The original article [1] has been corrected.

\section{Author details}

${ }^{1}$ Faculty of Sport and Health Science, Ritsumeikan University, Kusatsu, Shiga, Japan. ${ }^{2}$ Faculty of Sport Science, Nippon Sport Science University, Yokohama, Kanagawa, Japan.

Published online: 09 July 2021

\section{Reference}

1. Hori M, Suga T, Terada M, et al. Relationship of the knee extensor strength but not the quadriceps femoris muscularity with sprint performance in sprinters: a reexamination and extension. BMC Sports Sci Med Rehabil. 2021; 13:67. https://doi.org/10.1186/s13102-021-00293-1.

The original article can be found online at https://doi.org/10.1186/s13102021-00293-1.

* Correspondence: t-suga@fcritsumei.ac.jp

${ }^{1}$ Faculty of Sport and Health Science, Ritsumeikan University, Kusatsu, Shiga, Japan

Full list of author information is available at the end of the article

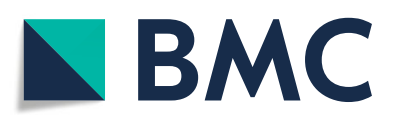

(- The Author(s). 2021 Open Access This article is licensed under a Creative Commons Attribution 4.0 International License, which permits use, sharing, adaptation, distribution and reproduction in any medium or format, as long as you give appropriate credit to the original author(s) and the source, provide a link to the Creative Commons licence, and indicate if changes were made. The images or other third party material in this article are included in the article's Creative Commons licence, unless indicated otherwise in a credit line to the material. If material is not included in the article's Creative Commons licence and your intended use is not permitted by statutory regulation or exceeds the permitted use, you will need to obtain permission directly from the copyright holder. To view a copy of this licence, visit http://creativecommons.org/licenses/by/4.0/. The Creative Commons Public Domain Dedication waiver (http://creativecommons.org/publicdomain/zero/1.0/) applies to the data made available in this article, unless otherwise stated in a credit line to the data. 